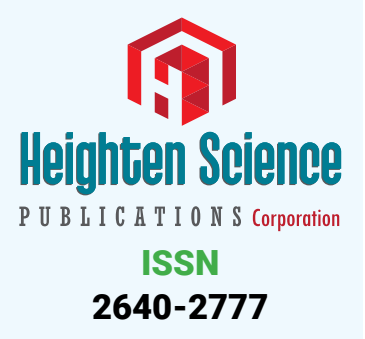

*Address for Correspondence: Dr. Sudhakar Pattanaik, Chintamani Bhawan, RC Das Lane, Kamapalli, Brahmapur, PIN: 760004, Odisha, India, Tel: 00-91-7381342829; Email: drspattanaik@yahoo.co.uk

Submitted: 13 April 2017

Approved: 23 June 2017

Published: 27 June 2017

Copyright: @ 2017 Pattanaik S. This is an open access article distributed under the Creative Commons Attribution License, which permits unrestricted use, distribution, and reproduction in any medium, provided the original work is properly cited

Abbreviations: BMS: Burning Mouth Syndrome; OSF: Oral Submucous Fibrosis; OL: Oral Leukoplakia; PIL: Paucibacillary Indeterminate form of Leprosy; PAR: Primary Atrophic Rhinitis; ROM: Rifampicin Ofloxacin and Minicycline; MDT Rifampicin Clofazimine and Dapsone-Multi Drug Therapy

D) Check for updates
Research Article

\section{A possible Etiology and new treatment of Burning Mouth Syndrome and allied condition}

\author{
Sudhakar Pattanaik* \\ Retired Professor, MKCG Medical College, Brahmapur, Odisha, India
}

\section{ABSTACT}

Introduction: Burning mouth syndrome, oral sub mucous fibrosis, leukoplakia, etc are the different manifestations of a common disease as per the surmise of various authors. There is no known cause and no specific treatment. Attempt is made in this study to find a cause and if possible, a treatment.

Materials and methods: 38 such cases were taken up in this study. It was found, that the cardinal signs of paucibacillar indeterminate form of Hanseniasis, as per the definition of WHO, are present in all these cases. Also they are found to respond well to the anti-leprotic drugs prescribed by WHO for the Hanseniasis.

Conclusion: It is recommended for multicentre trial and further research on this score which would relieve the suffering millions of the world populations.

\section{INTRODUCTION}

Burning sensation in the mouth, recurrent apthus ulceration, excessive intolerance to spices and peppers, scarring of oral mucosa, trismus (stenotic), melanotic mucosal pigmentations, loss of sensation of taste-one or more all of these clinical manifestations may make a patient suffer from the burning pain in mouth, tongue and throat. In it's acute from the pain and dysphagia is terribly agonizing. He is hungry, realizes the pleasant flavor of the dishes served to him but he fears to put a grain into his mouth as it may make a start of unbearable pain-the Burning Mouth Syndrome. Patient developing severe and alarming marasmic condition due to malnutrition is frequently found. Such patients frequenting clinics of an ENT surgeon is a common find. They very often report only after failure from specialists of medicine, dentistry or other ENT surgeons and doctors of other pathies and even sorcerers. There is no specific treatment for these conditions and so the ENT surgeon finds himself at the end of his tether. The despair and mercy call of the patient persuade the doctor to beat about the bush like others. Unnecessary or toxic drugs or mutilating operations are the result. The most dangerous prognosis of the diseases is the transformation to malignancy. The present paper finds a successful treatment that was found during his earlier study on nasal Hanseniatic manifestation-the Primary Atrophic Rhinitis (PAR) [6]. Naturally this treatment carries its points towards the diagnosis of the causative factor of the disease that was never suspected earlier.

\section{REVIEW OF LITERATURE}

There are no clear-cut distinguishing features among Burning Mouth Syndrome (BMS), Oral Submucous Fibrosis (OSF), and Oral Leukoplakia (OL) and other such diseases [1,2]. OL is considered a sequel of OSF by many authorities [3]. Similarly betel quid chewing and smoking being the common causative factors of OSF and OL 
makes the two diseases to be of a common origin [4]. These diseases have some of their symptomatology and histopathology findings different from each other but the site of affection, most of the clinical features, suspected etiologies and the treatment modalities are almost similar. A disease to which the above syndromes are linked in this study is paucibacillary inderminate Leprosy (PIL) which is considered a form of diseases of leprosy. Hanseniasis sometimes affects cranial nerves and produces widely variant symptomatology [5]. It manifests as different diseases with symptoms like loss of taste, anosmia, ulceration, and loss of tactile sensation of mouth, pharynx and tongue. Other widely variant manifestations like facial palsy, corneal opacity, nerve deafness or conductive deafness of Eustachian origin also occur. The Trigeminal, Facial, Glossopharygeal and Vagus are the main nerves supplying sensory, motor and secreto-motor fibers to the mouth, tongue, pharynx, larynx and nose. So affections of these organs produce pain (frequently burning that causes dysphagia), loss of taste, dryness and vasomotor disturbances producing ulcer scarring and trismus. All these are found in BMS, OSF and OL. Further support on this score is the nasal disease like PAR. All these were considered idiopathic is now found to be of Hanseniatic [6].

The very name of leprosy (Hanseniasis) is frightening; suspicion of this infection makes a person feel himself in an inferno and an infected person is considered a social outcast. But these entire notions are nullified now. The diseases, in most of its manifestations, are benign now-as benign as common cold. Only a very small percentage of cases pass on to its severest manifestation-the lepromatuse Leprosy (LL), which cripples the patient, disfigures him with foul smelling ulcers that destroy his fingers, toes, lips, ears and what not? Only a few decades back this disease had no treatment. But now there is very simple and cheap treatment and that too only for a limited period-the fixed duration MDT. It cures, even the lepromatous from within six months to one year.

In the most benign form of Hanseniasis i.e. Paucibacillary Indeterminate form, it may be with little or non-perceptible symptomatology. A person suffering from it may lead a happy and healthy normal life. And if he gets a few of its manifestations like one or two hypopigmented skin patches or localize anesthetic areas of skin or a few nerve thickenings or tenderness he will be cured with a single dose of ROM (Rifampicin, Ofloxacin and Minicyclne) [7]. Also there may be frequent self cure [8]. The definitions which are recommended in relation to early diagnosis of leprosy by the committee of WHO are (a) single or multiple hypopigmented or erythematous lesions not typical of other skin diseases; (b) loss of sensation (thermal, pain and touch) with or without skin lesion; and(c) enlarged nerve, either trunk or cutaneous. Further recommendations of WHO are (A) Suspect leprosy: Leprosy should be suspected if only one cardinal sign of leprosy is found. (B) Early leprosy is present if two cardinal features but no disability are found. In early paucibacillary leprosy the number of lesions should be limited; in early multibacillary leprosy, infiltration should be mild.

\section{MATERIALS AND METHODS}

Cases, clinically diagnosed (histologycally substantiated as needed), as BMS or OSF or OL who had failed to obtain relief by presently prevailing treatment are taken up. New cases seeking treatment were first tried with prevailing therapies; those who failed to get relief were included in this study. All the patients were assessed for the presence of the cardinal signs of Hanseniasis. The results are recorded in table 2. The drugs tried were anti-leprotic drugs as per Multi-drugs therapy (MDT) [9], which includes rifampicin, dapsone and clofazimine in there therapeutic doses with due consideration of age, nutritional status and tolerance. In some cases where patient express reluctance to accept long term flow up ROM- rifampicin, ofloxacine and minicycline-the drugs recommended for the benign forms i.e. the paucibacillary indeterminate form is administered. Since immunological tests are not accepted as diagnostic tools it was not tried in this study. 


\section{The result of therapy is assessed as:}

(i) Perceptible relief: when the patient feels that he gets some relief but the doctor fails to appreciate the clinical features of improvement.

(ii) Satisfactory relief: when the patient feels happy and quite satisfied with the relief and the surgeon find some improvement in clinical sign and symptoms.

(iii) Cured: - when the patient gets all symptoms relieved and the surgeon finds that most of the clinical features are cured. Usually touch sensation rarely return to anesthetic areas.

Special note: Some of the patients, who are found clinically improved but are not satisfied with their symptom relief, get satisfaction with addition of tranquilizers.

The results are recorded in tables below.

The period of study was from Oct. 1990 to July 2004 i.e. 15 years.

The number of case included in the study was 94 but only 38 cases could fulfill the criteria of the study. Many cases when obtain partial relief prefer to pursue their profession, often bread earning, than to go through the ordeals of repeated medical check-up and completing the course. They were not included in the study.

\section{RESULT AND DISCUSSION}

Table 1 showing age distribution of different cases. It indicates that the OSF is more common than BMS and OL. BMS, being a symptom in OSF also, may be considered at the top of the list. The high incidence of the disease is in third and fifth decade of life.

Table 2 showing the presence of the cardinal signs of PIL. The loss of touch sensation is found in all cases. The common sites found anesthetic are terminal phalanx, ankle joint, foot and $4^{\text {th }}$ metacarpophalangeal joints in that order. 20 to 25 cotton fibers touch the area to determine anesthesia. The pin prick and pressure sensation were inconclusive and in some cases only [10-12]. It being frequently erratic, was abandoned.

Since 2 or more cardinal signs are present in all these cases of burning mouth syndrome and allied diseases they could be considered as the manifestations of early leprosy as per the expert committee of WHO [8].

Table 3 results of treatment. It shows that the effect of anti-leprosy drugs starts as early as one month. A case of cure within one month's therapy was found. World literature reveals no satisfactory treatment for BMS. The result found in the study is quite successful.

Table 1: The distribution of different cases total cases studied-38.

\begin{tabular}{|c|c|c|c|c|c|}
\hline Distribution of number of case & \multicolumn{7}{|c|}{ Ageincidence } \\
\cline { 2 - 6 } & $\mathbf{1 0}$ to $\mathbf{1 9}$ & $\mathbf{2 0}$ to $\mathbf{2 9}$ & $\mathbf{3 0}$ to $\mathbf{3 9}$ & $\mathbf{4 0}$ to $\mathbf{4 9}$ & $\mathbf{5 0}$ above \\
\hline Bms- $10(26 \%)$ & $\mathrm{Nil}$ & 3 & 3 & 2 & 2 \\
\hline Osf - 20(53\%) & 5 & 5 & 1 & 5 & 4 \\
\hline Ol - $8(21 \%)$ & $\mathrm{Nil}$ & 4 & Nil & 2 & 2 \\
\hline Total- 38 & 5 & 12 & 4 & 9 & 8 \\
\hline $100 \%$ & $13 \%$ & $32 \%$ & $10 \%$ & $24 \%$ & $21 \%$ \\
\hline
\end{tabular}

Table 2: Presence of cardinal signs of early hanseniasis.

Loss of sensation Nerve enlargement Skin patches Only one sign Two signs More than two signs Touch Thermal

\begin{tabular}{|c|c|c|c|c|c|c|}
\hline All & 27 & 27 & 5 & Nil & 33 & 5 \\
\hline $100 \%$ & $71 \%$ & $71 \%$ & $13 \%$ & Nil & $87 \%$ & $13 \%$ \\
\hline
\end{tabular}




\begin{tabular}{|c|c|c|c|c|c|c|}
\hline \multirow{2}{*}{$\begin{array}{c}\text { Diseases } \& \\
\text { number of cases }\end{array}$} & \multicolumn{6}{|c|}{ Results noted during the treatment } \\
\hline & Results observed & $\begin{array}{l}\text { After } 1^{\text {st }} \\
\text { month }\end{array}$ & $\begin{array}{c}3^{\text {rd }} \\
\text { month }\end{array}$ & $\begin{array}{c}5^{\text {th }} \\
\text { month }\end{array}$ & $6^{\text {th }}$ month & Within a year \\
\hline Osf - 20 & $\begin{array}{l}\text { Perceptible satisfactry } \\
\text { cured otherwise }\end{array}$ & $\begin{array}{l}5 \\
X \\
X\end{array}$ & $\begin{array}{l}6 \\
7 \\
2\end{array}$ & $\begin{array}{l}1 \\
2 \\
6\end{array}$ & $\begin{array}{c}\text { X } \\
2 \\
8 \\
\text { No relief }-1\end{array}$ & $\begin{array}{c}\mathrm{X} \\
2 \\
2 \\
\text { Recurrence- 1 }\end{array}$ \\
\hline Bms - & $\begin{array}{l}\text { Perceptible satisfactry } \\
\text { cured otherwise }\end{array}$ & $\begin{array}{l}2 \\
1 \\
1\end{array}$ & $\begin{array}{l}4 \\
2 \\
1\end{array}$ & $\begin{array}{l}x \\
x \\
3\end{array}$ & $\begin{array}{l}X \\
X \\
5\end{array}$ & $\begin{array}{l}X \\
X \\
X\end{array}$ \\
\hline Ol -8 & $\begin{array}{l}\text { Perceptible satisfactry } \\
\text { cured otherwise }\end{array}$ & $\begin{array}{l}5 \\
1 \\
\times\end{array}$ & $\begin{array}{l}1 \\
4 \\
1\end{array}$ & $\begin{array}{l}x \\
x \\
1\end{array}$ & $\begin{array}{c}\mathrm{X} \\
\mathrm{X} \\
3 \\
\text { One turend } \\
\text { malignant }\end{array}$ & $\begin{array}{l}X \\
X \\
X\end{array}$ \\
\hline Total - 38 & $\begin{array}{l}\text { Perceptible satisfactry } \\
\text { cured otherwise }\end{array}$ & $\begin{array}{c}12 \\
1 \\
1\end{array}$ & $\begin{array}{c}11 \\
13 \\
4\end{array}$ & $\begin{array}{c}1 \\
2 \\
10\end{array}$ & $\begin{array}{c}X \\
2 \\
16 \\
2\end{array}$ & $\begin{array}{l}X \\
X \\
X \\
1\end{array}$ \\
\hline
\end{tabular}

Final results in 6 months are

1. BMS - all cured

2. OSF - $80 \%$ cured

\section{Leukoplakia - $60 \%$ cured}

These are quite encouraging results.

No case reported severe aggravation or any drug induced reaction. And some minor such cases were managed by temporary withdrawals or administration of needful drugs like corticosteroids. Additional treatments including drugs like tranquilizers, vasodilators, neurotrophic drugs and hematinics. Some of these cases were found to continue their habits of addiction to tobacco; they were restricted. One case turned malignant. He was having the diseases for 6 years and treated by many doctors and various institutions including some premier institutes of India. He had an indolent ulcer cheek in addition to oral problems. Frequent biopsy from ulcer revealed OL only, on all previous occasions. He was referred to TATA cancer institute Mumbai when the ulcer aggravated suddenly. He was treated and was cure there.

\section{Other note-worthy points}

In countries like USA leprosy is very rare. But these diseases are almost equal to that of other countries in the World. The other possibility that there may be some other diseases like leprosy (Para- leprosy infection) might be there. Subsequent research would reveal further. A recent observation on NonTuberculr Myco bacterium (NTM) now puts doubt on the concept of early paucibacillary indeterminate leprosy.

\section{SUMMARY AND CONCLUSION}

Burning mouth syndrome and allied diseases are the manifestations of benign form of Hansenisis (PIL) as found in this study. The recently found Non tubercular mycobacterium appears other possibility. The place of this work is in Odisha, a province of India where leprosy is endemic. Also betel quid chewing and tobacco (in form of gutka and county cigarette) is suspected as one of the causative factors which are more prevalent here. So multicenteric research to verify, add and suggest further on this study would be a boon for the suffering millions.

The outcome of the study appears a boon to the suffering millions of the world population since no specific treatment is found till date [12]. 


\section{REFERENCES}

1. Zakzewaska JM. The burning mouth syndrome remains an enigma. Pain. 1995; 62: 253-257. Ref.: https://goo.gl/v86cC3

2. Grushka M, Epstein JB, Gorsky M. Burning mouth syndrome. American Family Physician. 2002; 65: 615-620. Ref.: https://goo.gl/m268Tb

3. Macaron N, Arbiser J, Howard A. Oral sub mucous fibrosis. E Medicine July. 2003; 21: 1-15.

4. Lee $\mathrm{CH}$, Ko YC, Huang HL, Chao YY, Tsai CC, et al. The precancer risk of betel quid chewing, tobacco use and alcohol consumption in oral leukoplakia and oral submucoucous fibrosis in southern Taiwan. British Journal of cancer. 2003; 88: 366 -372. Ref.: https://goo.gl/N4pRUJ

5. Gopinath DV, Thappa DM, Jaishankar TJ. A clinical study of the involvement of cranial nerves in leprosy. Indian J Lepr. 2004; 76: 1-9. Ref.: https://goo.gl/Rz1Uza

6. Pattanaik S. Interesting obserbations on Primary Atrophic Rhinitis. Indian Journal of Otolaryngology and Head and Neck surgery. 2006; 58: 264-267. Ref.: https://goo.gl/EDe85y

7. WHO. Expert Committee on Leprosy: seventh Report. WHO tech rep ser No. 847 World Health Organization. Geneva. 1998. Ref.: https://goo.gl/RKw8Wx

8. WHO. Report of the consultation on the early diagnosis of leprosy. Geneva. 1990; 90.2: 11-12. Ref.: https://goo.gl/wzQM8k

9. WHO. Chemotherapy of leprosy for control programmes. WHO Tech Rep Ser No. 675. World Health Organization, Geneva. 1982; Ref.: https://goo.gl/2f59zz

10. Tzourio C, Henry P, Boucher P, Parent M, Millan J, et al. Lepre Lepromateuse: arguments cliniquee et electrophysiologiques en favour $d^{\prime}$ une multineverite axonel. Acta leprol. 1989; 7: 51-56. Ref.: https://goo.gl/eQhcJF

11. Grimaud J, Blum L, Verchaud B, Diop A, Millan J. Depster et surveillar une neuropathiie Hansenienne: queitestcoisir? Acta Leprol. 1992; 8: 17-22. Ref.: https://goo.gl/QGtY6W

12. Zakrzewska JM, Forssell H, Glenny AM. Interventions for the treatment of burning mouth syndrome. Cochrane Database Syst Rev. 2005; 25: Ref.: https://goo.gl/8qYyDJ 